\title{
Domestic Violence and Abuse against Married Women in Konjyosom Rural Municipality of Lalitpur District
}

\author{
Pradip Parajuli, PhD
}

Principal Author

Associate Professor,Tribhuvan University

Ganga K. C., PhD

Corresponding Author

Associate Professor, Tribhuvan University

Email: gangakc1968@gmail.com

\begin{abstract}
Domestic violence has been a perennial experience among the women especially in developing countries. This includes both physical attack and coercive behavior which give rise to physical, sexual, and psychological impacts including depression, emotional distress, eating and sleeping disturbance, and physical symptoms, such as headaches and stomach aches. The present paper tries to explore the level of domestic abuses experienced by the married women Konjyosom Rural Municipality of Lalitpur. This study was based on exploratory and descriptive research design which is carried out in a Rural Municipality of Lalitpur district. This paper was conducted to examine the level of domestic violence and abuse which a married woman had to go through with their experience. This study reports that the married women are subject to domestic abuses of different kinds regardless of the ages, background, castelethnicity, religion, education level, occupation, and class.
\end{abstract}

Keywords: abuse, domestic violence, experience, knowledge, married women

\section{Introduction}

Violence is the presence of physical or verbal strength against self or other compelling act against one's will on pain of being hurt. The meaning of the violence purely tells to any kind of oppression, coercion, and cruelty against another being. Violence is focused towards the women including the girl child and the old women. Violence against women is a universal issue. The difference is only in nature and its extent. This includes not only physical violence but also the mental and emotional violence that arises due to prejudiced attitudes being formed from the patriarchal society from the tradition, which affects every aspect of the women throughout their lives. This abuse of patriarchal power by the family up to the government itself is committed because of the fact that most of the victims are women. That contains violence committed by a spouse, family members, 
Domestic Violence and Abuse agnaist Married Women in Konjyosom Rular Muanacipality of Lalitpur District : Parajuli \& K.C. $\mid 109$

and manifested through sexual, physical, psychological, economic abuse (Garcia et al., 2006). Globally, it has been a subject of research interest since the 1970s but the detailed data indices are low in the developing world.

Violence against women is recognizing as attendance of historically unequal power relation between men and women, which have led to domination over and discrimination against women by men and to the avoidance of the full advancement of females, and that violence against women is one of the dynamic social mechanisms by which women are enforced into a inferior position compared with men (UN, 1993). Domestic violence is one of the most important issues in public health and human rights discussions; it involves violence or domination by one person against another person in a domestic context. Women and girls are mostly the first victims of domestic violence (Rahnavardi et al., 2017). Domestic violence against women includes physical, sexual abuse, emotional or verbal abuse, and economic violence (Bohra, 2015).

Domestic violence and abuse have not only upsetting societal problem but also a severe medical as well as mental health problem appears worldwide. Nepalese Ministry of Law and Justice describes domestic violence as a practice of gender-based violence that includes physical, mental, sexual, emotional, or economic harm committed by one family member on another.

Violence, in contradiction of women, means any act of gender-based violence which consequences in physical, sexual or psychological damage or suffering to women, including burdens of such acts, pressure or arbitrary deprivation of liberty, whether occurring in public or private life (UN, 1993).

Violence against women refers to any type of damaging behavior directed towards women and girls. Such violence is deeply embedded and rooted in cultural, psychological, political, and sociological bases in our society. Furthermore women are treated as sex objects to be exploited as thumping bags to ease frustration, abuse to satisfy a sexual desire (WOREC, 2009).

Domestic violence is in every community or societies across the world but is more universal in developing countries. It has fully-fledged to be a serious and burning subject in Nepal. The recognition of women as second class citizens in the patriarchal Nepalese society and the social value that puts husband at higher social status, and allows them to dominate their wives has escalated domestic violence against women in Nepal. Domestic violence has affected women of all ages, background, class, caste, religion, and society. The literature describes this as a result of women's negligence, general ignorance, and lack of thoughtful about domestic violence. Women's illiteracy, lack of education, low 
110| THE BATUK : A Peer Reviewed Journal of Interdisciplinary Studies $\quad$ Vol. $6 \quad$ Issue No. 2 July 2020 ISSN 2392-4802 mobility, and lack of awareness about their rights as a human being have led them to tolerate the day to day violence as their hardship. The low social position of women has been a key barrier in realizing their rights, and raising voices against their rights violations such as the day to day domestic violence (Ministry of Health and Population. 2012).

Violence against women started being openly discussed and addressed in a discourse in Nepal from last few decades. The general out of bounds of not accepting this form of violence was related to a solid patriarchal society and partial freedom of expression and mobility of such social ills. It has therefore been openly discussed as the most common form of gender-based violence as domestic violence, or gender-based violence in families (Sapkota, 2011).

Male dominance is a deeply rooted cultural norm and values in Nepali society. Features of this male dominance include control over women's sexuality, early marriages, dowryrelated common cultural practices, and cultural values and norms that require women's submissive role in the family. It also means that intimate partner/ husband violence is an open-secret in Nepali society. Historically and culturally, women generally accept violence from their husbands, and this fact is kept inside the home (Sharma, 2002). Gender-based violence remains prevalent and ingrained in much of Nepali life (Ghimire \& Samuels, 2017). Paudel (2007) found that the one-third (35 percent) of women in Nepal experience gender-based violence at home.

\section{Objectives of the Study}

The broad objective of this study is to examine the knowledge and experience of domestic violence and abuse against married women in the study area. However, the study has some specific objectives. They are:

- To examine the level of knowledge of domestic violence and abuse against married women in the study area.

- To analyze experience of domestic violence and abuse against married women in the study area.

\section{Research Methods}

This study is based on the exploratory and descriptive research design which is carried out in Konjyosom Rural Municipality-3 of Lalitpur district of Bagmati Province of Nepal. All together 40 house-holds were selected purposively. Only married women were taken as respondents. Primary qualitative as well as quantitative data were collected by the use of interview and observation methods. 
Domestic Violence and Abuse agnaist Married Women in Konjyosom Rular Muanacipality of Lalitpur District : Parajuli \& K.C. $\mid 111$

\section{Respondents Profile}

The demographic characteristics include age, sex, and marital status of the respondents. Results as shown in Table 1 revealed that out of 40, half of the respondents are in the age group of 20-45. Only 14 respondents fall under the age group of below 19, and the rest are of above 45 years of age.

Table 1

Socio Demographic Profile of the Respondents

\begin{tabular}{|c|c|c|c|}
\hline \multicolumn{2}{|c|}{ Socio-demographic Profile } & \multirow{2}{*}{$\begin{array}{l}\text { Frequency } \\
14\end{array}$} & \multirow{2}{*}{$\begin{array}{l}\text { Percentage } \\
35\end{array}$} \\
\hline \multirow{3}{*}{ Age group } & Below 19 & & \\
\hline & 20 to 45 & 20 & 50 \\
\hline & 45 above & 6 & 15 \\
\hline \multirow{5}{*}{ Caste/ethnicity } & Brahmin & 8 & 20 \\
\hline & Chhetri & 8 & 20 \\
\hline & Damai/ Kami/Sarki & 4 & 10 \\
\hline & Gurung/Magar/Tamang & 14 & 35 \\
\hline & Newar & 6 & 15 \\
\hline \multirow{3}{*}{ Religion } & Hindu & 20 & 50 \\
\hline & Buddhist & 13 & 32.5 \\
\hline & Christian & 7 & 17.5 \\
\hline \multirow{3}{*}{ Education } & Illiterate & 8 & 20 \\
\hline & Up to school level & 26 & 65 \\
\hline & Higher education & 6 & 15 \\
\hline \multirow{3}{*}{ Occupation } & Agriculture/ animal husbandry & 21 & 52.5 \\
\hline & Wage labour/ household work & 8 & 20 \\
\hline & Service/ business/ industries & 11 & 27.5 \\
\hline Economic & Low & 19 & 47.5 \\
\hline \multirow{2}{*}{$\begin{array}{l}\text { Status of } \\
\text { family }\end{array}$} & Medium & 12 & 30 \\
\hline & High & 9 & 22.5 \\
\hline
\end{tabular}

Along with these demographic characteristics, caste/ethnicity, religion, education, occupation, and family economic status of respondents were taken as socio-economic status. The Table 1 shows that $35 \%$, which is the majority of the respondents, are Gurung/Magar/Tamang. Ten percent of the respondents are respectively Brahmin and Chhetri, 15\% are Newar, and only 4 respondents are from the Damai/Kami/Sarki ethnic/caste group. Half of the respondents are from the Hindu religion, $32.50 \%$ are Buddhist religions, and 7 are Christians. A total of 26 respondents have completed their 
school-level education. Among them, 20\% respondents are literate and only a few of them have higher level educational qualification. More than half of respondents are involved in agriculture/animal husbandry, $27.5 \%$ respondents are involved in service/business/ industries, and $20 \%$ are involved in wage labor/household domestic work. Among them, $47.5 \%$ respondents belong to low economic status family, and $30 \%$ belong to medium class family.

\section{Knowledge of Domestic Violence and Abuse}

To examine the level of knowledge on domestic violence and abuse, respondents were asked knowledge on domestic violence and abuse, knowledge on domestic violence and abuse as a serious gender issue, knowledge on forms of physical violence and abuse, knowledge on reporting for help, knowledge on the law against domestic violence and abuse, knowledge on organizations working against domestic violence and abuse, knowledge on the reasons of domestic violence and abuse, knowledge on the impact of domestic violence and abuse, and knowledge on unwanted sex considered hereunder.

Table 2

Distribution of the Respondents by Knowledge of Domestic Violence and Abuse

\begin{tabular}{llll}
\hline Variables & Classification & Frequency & Percentage \\
\hline Knowledge on domestic violence and & Have knowledge & 38 & 95 \\
& Don't have knowledge & 2 & 5 \\
\hline Knowledge on domestic violence and & Have knowledge & 35 & 87.5 \\
abuse as a serious gender issue & Don't have knowledge & 5 & 12.5 \\
\hline Knowledge of forms of physical & Have knowledge & 30 & 75 \\
violence and abuse & Don't have knowledge & 10 & 25 \\
\hline \multirow{2}{*}{ Knowledge on reporting for help } & Have knowledge & 20 & 50 \\
& Don't have knowledge & 20 & 50 \\
\hline Knowledge of the law against domestic & Have knowledge & 5 & 12.5 \\
violence and abuse & Don't have knowledge & 35 & 87.5 \\
\hline Knowledge of organizations working & Have knowledge & 7 & 17.5 \\
against domestic violence and abuse & Don't have knowledge & 33 & 82.5 \\
\hline Knowledge of the reasons for domestic & Have knowledge & 32 & 80 \\
violence and abuse & Don't have knowledge & 8 & 20 \\
\hline Knowledge on the Impact of domestic & Have knowledge & 22 & 55 \\
violence and abuse & Don't have knowledge & 18 & 45 \\
\hline \multirow{2}{*}{ Knowledge of unwanted sex } & Have knowledge & 32 & 80 \\
& Don't have knowledge & 8 & 20 \\
\hline
\end{tabular}


Domestic Violence and Abuse agnaist Married Women in Konjyosom Rular Muanacipality of Lalitpur District : Parajuli \& K.C. $\mid 113$

Table 2 disclosed that the majority of the participants (95\%) have knowledge of domestic violence and abuse. Five percent of them are found to be unaware of it. Similarly, 12.5 percent of the respondents do not know that the issue is considered as a serious gender issue. Majority of the participants (75\%) reported that they have knowledge on forms of physical violence and abuse. More importantly, only half of the respondents reported that they have knowledge on reporting for help. Likewise, a large number $(87.5 \%)$ of participants reported that they don't have the knowledge on the legal provisions against domestic violence and abuse. On the other hand, majority of them $(82.5 \%)$ are unaware of the organizations working against the issue.

Similarly, eighty percent of the participants reported that they have knowledge on the reasons for domestic violence and abuse. More than half respondents $(55 \%)$ reported that they have knowledge on the impact of domestic violence and abuse. Accordingly, twenty percent of the respondents reported that they do not have knowledge of unwanted sex.

\section{Experience of Domestic Violence and Abuse}

To analyze the women's experience of domestic violence and abuse, respondents were asked experienced of domestic violence and abuse, frequently experienced domestic violence and abuse, types of physical violence and abuse experienced, experienced violence and abuse of sexual activities, experienced of belittling or humiliating, experienced of restriction on mobility or any activities, experienced of insulted and feeling bad, experience of taken earnings or savings, and experience of refused to give money for households expenses. Response is shown in Table 3.

The data shows that out of the total participants, $90 \%$ reported that they have experienced domestic violence and abuse. Twelve participants reported that they have experienced domestic violence frequently. Respondents who have (frequently) experienced domestic violence and abuse reported that pushing/shoving pulling hair/slapping, kick on the abdomen/beating/choking, and thrown something at/attempted burning are the types of violence they experienced. In the mean time, 25 percent of the respondents reported that they have experienced violence and abuse of sexual activities. Majority of the respondents reported that they have the experience of being humiliated $(70 \%)$, restriction mobility $(60 \%)$, and insulted (85\%). More than half respondents reported that they have experience of taking their earnings/saving by others as well as the experience of not receiving money from the family member for household activities. 
Table 3

Distribution of the Respondents by Experience of Domestic Violence and Abuse

\begin{tabular}{|c|c|c|c|}
\hline Variables & Classification & Frequency & Percentage \\
\hline \multirow{2}{*}{$\begin{array}{l}\text { Experienced of domestic violence and } \\
\text { abuse }\end{array}$} & Yes & 36 & 90 \\
\hline & No & 4 & 10 \\
\hline \multirow{2}{*}{$\begin{array}{l}\text { Frequently experienced domestic } \\
\text { violence and abuse }\end{array}$} & Yes & 12 & 30 \\
\hline & No & 28 & 70 \\
\hline \multirow{2}{*}{$\begin{array}{l}\text { Experienced violence and abuse of } \\
\text { sexual activities }\end{array}$} & Yes & 10 & 25 \\
\hline & No & 30 & 75 \\
\hline \multirow{2}{*}{ Experienced of belittling or humiliating } & Yes & 28 & 70 \\
\hline & No & 12 & 30 \\
\hline \multirow{2}{*}{$\begin{array}{l}\text { Experienced of restriction on mobility } \\
\text { or any activities }\end{array}$} & Yes & 24 & 60 \\
\hline & No & 16 & 40 \\
\hline \multirow{2}{*}{ Experienced of insulted and feeling bad } & Yes & 34 & 85 \\
\hline & No & 6 & 15 \\
\hline \multirow{2}{*}{$\begin{array}{l}\text { Experience of taken earnings or } \\
\text { savings }\end{array}$} & Yes & 22 & 55 \\
\hline & No & 18 & 45 \\
\hline \multirow{2}{*}{$\begin{array}{l}\text { Experience of refused to give money } \\
\text { for households expenses }\end{array}$} & Yes & 21 & 52.5 \\
\hline & No & 19 & 47.5 \\
\hline
\end{tabular}

\section{Conclusion}

Domestic violence and abuse against married women are some of the most insidious forms of violence. It is prevalent in all societies. The study revealed that the women of all age, education, religion, ethnicity, and occupation are subject to the violence of all kinds. Snub, criticism, and mobility restrictions are found the most common problem they are experiencing in their daily life. It restricts women to the opportunity of empowerment, equality, development, and individual and societal peace.

\section{References}

Bohra, N., Sharma, I., Srivastave, S., Bhatia, M. S., Chaudhuri, U., Parial, S., Sharma, A., \& Kataria, D., (2015). Violence against women. Indian Journal of Psychiatry, 57, 333-338.

Garcia, M. C., Jansen, H., Ellsberg, M., Heise, L., Watts C. H., (2006). Prevalence of intimate partner violence: findings from the WHO multi-country study on women's health and domestic violence. Lancet.

Ghimire, A., \& Samuels, F., (2017). Understanding intimate partner violence in Nepal; prevalence, drivers and challenges. Overseas Development Institute, London. 
Domestic Violence and Abuse agnaist Married Women in Konjyosom Rular Muanacipality of Lalitpur District : Parajuli \& K.C. $\mid 115$

Ministry of Health and Population NE, ICF International. (2012). Nepal Demographic and Health Survey 2011 Kathmandu, Nepal and Calverton, Maryland, U.S.A.: Ministry of Health and Population, New ERA and ICF International.

Paudel, G. S. (2007). Domestic violence against women in Nepal. Gender, Technology and Development, 11(2), 199-233.

Rahnavardi, M., Shayan, A., Babaei, M., Khalesi, Z. B., Havasian, M. R., \& ahmadi, M., (2017). Investigating types and causes of domestic vionence against women and identifying strategies to deal with it from the perspective of victimes. Research Journal Pharm. And Tech., 10(10), 3637-3642.

Sapkota, S. (2011). Violence against Women- Focus on Domestic Violence. Health Prospect, IOM:Kathmandu.

Sharma, V. (2002). Human Rights Violation: A Global Phenomenon. New Dehli, India: APH Publishing Corporation

UN, (1993). Declaration on the Elimination of Violence against Women, United Nations Human Rights Office of the High Commissioner.

WOREC, (2009). Year Book Anbeshi, WOREC Nepal, Lalitpur. 